\title{
A Variant Form of Dens Invaginatus in Permanent Maxillary Canine
}

\author{
Bhuvaneswari Birla Bose ${ }^{1, *}$, Shivakumar. B ${ }^{2}$ \\ ${ }^{1}$ Department of Periodontics, Tagore Dental College \& Hospital, Chennai, India \\ ${ }^{2}$ Department of Periodontics, Ragas Dental College \& Hospital, Chennai, India \\ *Corresponding author: bhuvanabirla@gmail.com
}

Received July 25, 2014, 2014; Revised August 12, 2014; Accepted August 18, 2014

\begin{abstract}
Dens Invaginatus (DI) is a rare developmental anomaly, which presents as an infolding of enamel and dentine extending into the pulp chamber and sometimes into the root. The aim of this case report was to describe its radiographic findings, to emphasize the inexplicable morphology. Considering the likelihood of an early pulpal involvement and the chronic periapical lesions often associated with this anomaly without any clinical symptoms, dens invaginatus is clinically significant. Difficulties are encountered during the endodontic treatment, owing to the complex root canal anatomy. Therefore, a proper diagnosis and evaluation of the anomaly is essential to save the involved tooth.
\end{abstract}

Keywords: dens invaginatus, anomaly, diagnosis, dens in dente

Cite This Article: Bhuvaneswari Birla Bose, and Shivakumar. B, “A Variant Form of Dens Invaginatus in Permanent Maxillary Canine.” International Journal of Dental Sciences and Research, vol. 2, no. 4B (2014): 1-3. doi: 10.12691/ijdsr-2-4B-1.

\section{Introduction}

Dens invaginatus is a developmental anomaly that results in an enamel-lined cavity intruding into the crown or root prior to the mineralization phase. [1,2] Several aetiologic factors are proposed by the literature. These are stimulation with subsequent proliferation and in growth of cells of the enamel organ into the dental papilla; retardation of a focal group of cells, whilst those cells surrounding continue to proliferate normally during the dental development; external factors like trauma and infection; and also genetic factors. [3,4] On the basis of radiographic findings dens invaginatus was categorised as follows by Oehlers in 1957 [5].

Type I: The invagination is minimal and enamel-lined, it is confined within the crown of the tooth and does not extend beyond the level of the external amelo-cemental junction.

Type II: The invagination is enamel-lined and extends into the pulp chamber but remains within the root canal with no communication with the periodontal ligament.

Type IIIA: The invagination extends through the root and communicates laterally with the periodontal ligament space through a pseudo-foramen. There is usually no communication with the pulp, which lies compressed within the root.

Type IIIB: The invagination extends through the root and communicates with the periodontal ligament at the apical foramen. There is usually no communication with the pulp.
In Type III lesions, any infection within the invagination can lead to an inflammatory response within the periodontal tissues giving rise to a 'peri-invagination periodontitis'.

The most frequently affected tooth is the maxillary lateral incisor. [6] In a descending order of frequency, other teeth that develop this anomaly are the maxillary central incisors, premolars, canines, and molars. [2,6] The occurrence of this anomaly in mandibular teeth has been reported in a few cases. [4,7] The clinical appearance of dens invaginatus varies considerably. The crown of affected teeth can have normal morphology or it can also show unusual forms such as a greater buccolingual dimension, peg-shaped form, barrel-shaped form, conical shapes and talon cusps $[1,8]$.

This case report presents an unusual morphology of permanent maxillary canine with Type I dens invaginatus.

\section{Case Report}

An 18-year old male patient reported to the Department of Periodontics, Tagore Dental College, Chennai for routine oral prophylaxis. Patient was systemically healthy. On clinical oral examination, an unusual morphology of left maxillary canine was noticed. The canine width was large with a band of enamel on both facial and lingual aspect confluencing at the tip of the canine. (Figure 1 \& Figure 2).

The right maxillary canine presented normal morphology. The patient did not have any interference in occlusion or difficulty during mastication. The patient was not aware of the unaesthetic appearance of the maxillary 
canine. There was no familial history. The patient was unaware of any history of trauma during childhood. Clinical examination showed normal count of teeth in the maxillary arch. OPG and an intraoral periapical radiograph revealed the presence of invagination limited to the crown structure (Figure 3).

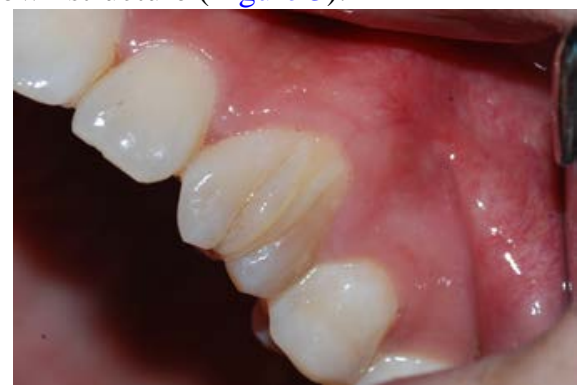

Figure 1. Labial view of the wide maxillary canine

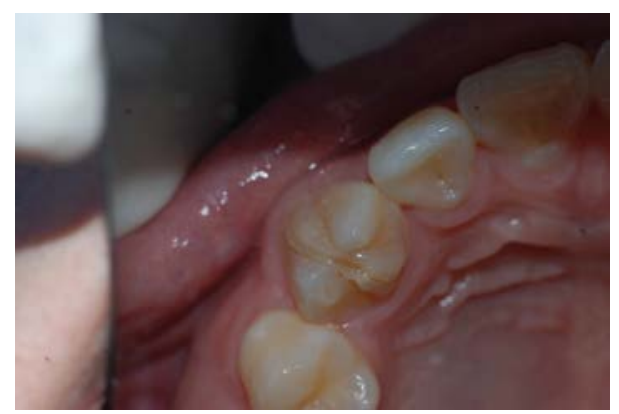

Figure 2. Occlusal view showing the band of enamel on the labial and lingual side converging at the canine tip

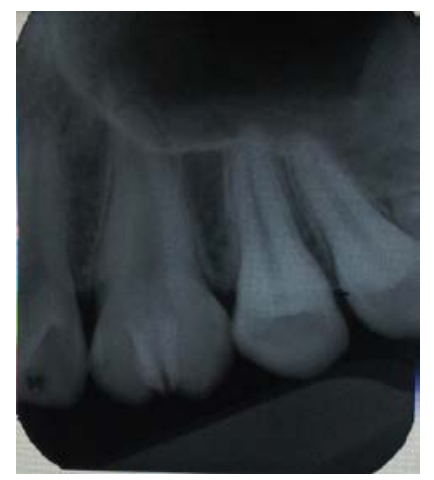

Figure 3. IOPA $x$-ray showing the invaginated enamel and widening of periodontal ligament

There is huge pulp chamber with widening of periodontal ligament. Oral prophylaxis was done and patient was kept under observation as patient was not willing for any treatment. Patient was explained about the complications such as increased risk of caries, pulpal pathosis and periodontal inflammation.

Routine recall visits are scheduled once in every six months to notice any change immediately.

\section{Discussion}

Dens invaginatus, otherwise termed as pregnant woman anomaly, extensive compound odontoma, and dens in dente, is a developmental anomaly that is due to the result of an invagination on the external surface of the tooth crown prior to calcification. [9,10,11] Its etiology is clearly unknown, yet it is alleged that compressed areas in permanent teeth during the formation and eruption process may result in dental crowns with peaks of invaginated enamel in the root canal. [12] Irritants can make its way through the thin area of enamel separating the pulp and predisposes to development of caries. Pulpal necrosis, abscess formation, cyst, and internal resorption are other complications $[13,14]$.

Several endodontic treatment options of dens invaginatus have been reported, including nonsurgical, surgical, and combined approaches. [15,16,17,18,19] In this case there was no caries nor any periapical pathology on the maxillary canine and the patient was also asymptomatic. Hence the patient did not undergo any intervention. However, meticulous monitoring is necessary due to the sequelae. Early diagnosis is important to prevent the need for possibly complex and difficult endodontic procedures at a later date.

\section{Conclusion}

It would appear that the exact aetiology of dens invaginatus is unknown although a genetic cause is probably the most likely factor. Similarly, the prevalence of the problem is uncertain and the nature of the invagination itself is mutable. Studies prove that the condition is associated with an increased prevalence of pulp disease and that any necessary endodontic treatment may be difficult because of aberrant anatomy. Obviously, there is a necessity for further scientific probing of this condition. There was no therapeutic intervention in this case due to patient's reluctance but in future there is a strong predisposition for treatment option. Dental clinicians should be well aware of these types of unusual morphologies presentation, in an attempt to salvage the tooth from loss.

\section{References}

[1] Y. P. Reddy, K. Karpagavinayagam, and C. V. Subbarao, "Management of dens invaginatus diagnosed by spiral computed tomography: a case report,” Journal of Endodontics, 34 (9). 11381142. Sep 2008.

[2] F. V. Vier-Pelisser, A. Pelisser, L. C. Recuero, M. V. So, M. G. Borba, and J. A. Figueiredo, "Use of cone beam computed tomography in the diagnosis, planning and follow up of a type III dens invaginatus case," International endodontic journal, 45 (2). 198-208. Feb 2012.

[3] A. Alani and K. Bishop, "Dens invaginatus. Part 1: classification, prevalence and aetiology,” International Endodontic Journal, 41 (12). 1123-1136. Dec 2008.

[4] C. C. Monteiro-Jardel and F. R. F. Alves, "Type III dens invaginatus in a mandibular incisor: a case report of a conventional endodontic treatment," Oral Surgery, Oral Medicine, Oral Pathology, Oral Radiology and Endodontology, 111(4). e29e32. 2011.

[5] F. A. C. Oehlers, "Dens invaginatus (dilated composite odontome). I. Variations of the invagination process and associated anterior crown forms," Oral Surgery, Oral Medicine, Oral Pathology, 10(11). 1204-1218. Nov 1957.

[6] S. C. Yeh, Y. T. Lin, and S. Y. Lu, "Dens invaginatus in the maxillary lateral incisor," Oral Surgery, Oral Medicine, Oral Pathology, Oral Radiology, and Endodontics, 87(5). 628-631. May 1999.

[7] B. Carvalho-Sousa, F. Almeida-Gomes, L. Gominho, and D. Albuquerque, "Endodontic treatment of a periradicular lesion on an invaginated type III mandibular lateral incisor," Indian Journal of Dental Research, 20(2). 243-245. 2009. 
[8] S. M. G. de Sousa and C. M. Bramante, "Dens invaginatus: treatment choices,” Endodontics and Dental Traumatology, 14(4). 152-158. Aug 1998

[9] S. R. Atkinson, "The permanent maxillary lateral incisor," American Journal of Orthodontics and Oral Surgery, 29 (12). 685-698. Dec 1943.

[10] E. J. Hovland and R. M. Block, "Nonrecognition and subse- quent endodontic treatment of dens invaginatus," Journal of Endodontics, 3 (9). 360-362. Sep 1977.

[11] G.-I. Hata and T. Toda, "Treatment of dens invaginatus by endodontic therapy, apicocurettage, and retrofilling," Journal of Endodontics, 13(9). 469-472. Sep 1987.

[12] W. G. Shafer, M. K. Hine, and B. M. Levy, A Textbook of Pathology, WB Saunders, Philadelphia, Pa, USA, 4th edition, 1983.

[13] G. Meighani and A. Pakdaman, "Diagnosis and management of supernumerary (mesiodens). A review of the literature,” Journal of Dentistry Tehran University of Medical Sciences, 7 (1) 41-49, Mar 2010.
[14] S. A. Sharma, "Mandibular midline supernumerary tooth: a case report," Journal of the Indian Society of Pedodontics and Preventive Dentistry, 19 (4). 143-144. 2001.

[15] F. A. C. Oehlers, "Dens invaginatus (dilated composite odontome). I. Variations of the invagination process and associated anterior crown forms," Oral Surgery, Oral Medicine, Oral Pathology, 10 (11). 1204-1218. 1957.

[16] E. Bimstein and A. Shteyer, "Dilated type of dens invaginatus in the permanent dentition: report of a case and review of the literature,” ASDC Journal of Dentistry for Children, 43 (6). 410 413. 1976.

[17] M. Caldari, C. Monaco, L. Ciocca, and R. Scotti, "Single- session treatment of a major complication of dens invaginatus: a case report," Quintessence International, 37 (5). 337-343. 2006.

[18] W. F. Swanson and F. M. McCarthy, "Bilateral dens in dente," Journal of Dental Research, 26. 167-171. 1947.

[19] D.J. Burton, R.O. Saffos, and R.B. Scheffer, "Multiplebilateral dens in dente as a factor in the etiology of multiple periapical lesions,” Oral Surgery Oral Medicine and Oral Pathology, 49 (6). 496-499. 1980. 